\title{
PENGARUH PARAMETER TEMPERATUR QUENCHING TERHADAP SIFAT MEKANIK DAN STRUKTUR MIKRO REAR HUB SPINDLES
}

\author{
${ }^{1}$ Murtalim , ${ }^{2}$ Fathan Mubina Dewadi ${ }^{3}$ Amir, ${ }^{4}$ Wanri Saputra Sigalingging \\ 1,2,3,4 Program Studi Teknik Mesin, \\ Fakultas Teknik dan Ilmu Komputer, UBP Karawang \\ Jl. HS.Ronggo Waluyo, Telukjambe Timur, Karawang, Jawa Barat 41361 \\ 1murtalim@ubpkarawang.ac.id \\ 2fathąn.mubina@ubpkarawang.ac.id \\ amir@ubpkarawang.ac.id \\ 4 tm19.wanrisigalingging@mhs.ubpkarawang.ac.id
}

\begin{abstract}
ABSTRAK
Perkembangan teknologi terutama dalam pengerasan logam mengalamai kemajuan yang sangat pesat. Perlakuan panas didefenisikan sebagai kombinasi operasi pemanasan dan pendinginan yang terkontrol dalam keadaan padat untuk mendapatkan sifat-sifat tertentu pada baja/logam atau paduan. Salah satu metode perlakuan panas tersebut dengan proses quenching. Proses perlakuan ini pada dasarnya terdiri dari beberapa tahapan, dimulai dengan pemanasan sampai ke temperatur tertentu, lalu diikuti dengan penahanan selama beberapa saat, baru kemudian dilakukan pendinginan dengan kecepatan tertentu.

Tujuan penelitian adalah untuk mengetahui perubahan sifat mekanik dan struktur mikro yang terjadi pada material rear hub spindle yang digunakan untuk gigi power thresher setelah megalami proses perlakuan panas dengan media pendinginan oli.

Dari hasil pengujian kekuatan bahan memperlihatkan bahwa nilai kekuatan tertingi terdapat pada specimen uji yang diberj perlakuan panas pada temperatur $875{ }^{\circ} \mathrm{C}$ dengan nilai kekuatan $602,46 \mathrm{~N} / \mathrm{mm}^{2}$ dan nilai kekuatan terkecil pada spesimen uji yang diberi proses perlakuan panas pada temperatur $825{ }^{0} \mathrm{C}$ dengan nilai kekuatan tarik $537,50 \mathrm{~N} / \mathrm{mm}^{2}$. Nilai kekerasan bahan tertinggi terdapat pada spesimen uji yang diberi perlakuan panas pada temperatur $875{ }^{\circ} \mathrm{C}$ dengan nilai kekerasan 219 HVN dan nilai kekerasan terkecil terjadi specimen uji yang diberi perlakuan panas pada temperatur $825{ }^{\circ} \mathrm{C}$ dengan nilai kekerasan $168 \mathrm{HVN}$.

Dari hasil pengujian mikro struktur memperlihatkan bahwa diameter butiran bahan menunjukkan menurunnya diameter butiran selama proses hardening dengan quenching oli dimana semakin kecil diameter butiran maka sifat mekanis bahan meningkat.
\end{abstract}

Kata Kunci : Rear Hub Spindles, Perlakuan panas, Sifat Mekanik, Struktur mikro 
Murtalim, Fathan Mubina Dewadi, Amir, Wanri Saputra Sigalingging

Vol. 5 No 2

ISSN : 2541-6995

E ISSN : 2580-5517

\section{PENDAHULUAN}

Seiring dengan perkembangan dunia industri yang semakin maju, mendorong para pelaku dunia industri untuk meningkatkan kebutuhan penggunaan dari hasil pengerasan baja yang dibutuhkan konsumen.

Perkembangan teknologi terutama dalam pengerasan logam mengalami kemajuan yang sangat pesat. Untuk memenuhi tuntutan konsumen dalam teknik pengerasan logam ini peneliti mencoba mengangkat permasalahan pengerasan logam pada baja karbon rendah, khususnya material rear hub spindles (poros roda belakang sepeda). Spindle ini sering digunakan oleh pengusaha power thresser (mesin perontok padi) sebagai material untuk komponen roda gigi mesin perontok padi. Kondisi di lapangan menunjukkanm masih rendahnya atau terbatasnya informasi teknologi yang diterima oleh petani atau pengguna (Ali 2017). Hal yang mendasari penelitian ini adalah sifat mekanis dari roda gigi power threser yang kurang baik, salah satunya kekuatan dan kekerasan yang tidak merata sehingga mengurangi kapasitas kerja proses perontokan padi (Sulistiaji 2007), begitu juga dengan biaya dan ketersediaan spare part (suku cadang) dari gigi perontok yang mahal dan sulit diperoleh oleh para pengusaha setempat.

Dari latar belakang di atas, perumusan masalah yang dapat diangkat adalah bagaimana menentukan parameter temperature proses perlakuan panas yang tepat agar dapat meningkatkan sifat mekanik material dan apakah material Rear hub spindles (poros roda belakang sepeda) yang di quenching akan dapat memperbaiki sifat ketahanan aus material.

Adapaun Tujuan dilakukan penelitian ini adalah untuk mengetahui sifat mekanik dan struktur mikro baja carbon rendah akibat perubahan variasi parameter temperatur perlakuan panas. Dan memberikan salah satu solusi atas penyediaan suku cadang gigi perontok dengan menggunakan Rear hub spindles 3/8 inch x 190 yang telah diperbaiki sifat mekanik materialnya.

Baja adalah logam paduan antara besi $(\mathrm{Fe})$ dan karbon $(\mathrm{C})$, dimana besi sebagai unsur dasar dan karbon sebagai unsur paduan utamanya. Kandungan karbon dalam baja berkisar antara $0,1 \%$ hingga $1,4 \%$ sesuai tingkatannya (Callister 2007). 
Murtalim, Fathan Mubina Dewadi, Amir, Wanri Saputra Sigalingging

Vol. 5 No 2

ISSN : 2541-6995

E ISSN : 2580-5517

Berdasarkan tinggi rendahnya presentase karbon di dalam baja, baja karbon diklasifikasikan sebagai berikut:

1. Baja Karbon Rendah (Low Carbon Steel) mengandung karbon antara 0,10 $-0,30 \%$. Baja karbon ini dalam perdagangan dibuat dalam plat baja, baja strip dan baja batangan atau profil.

2. Baja Karbon Menengah (Medium Carbon Steel) mengandung karbon antara $0,30 \%-0,60 \%$ C. Baja karbon menengah ini banyak digunakan untuk keperluan alatalat perkakas bagian mesin juga dapat digunakan untuk berbagai keperluan seperti untuk keperluan industri kendaraan, roda gigi, pegas dan sebagainya.

3. Baja Karbon Tinggi (High Carbon Steel) mengandung kadar karbon antara $0,60 \%-1,4 \% \mathrm{C}$ (Callister 2007). Baja ini mempunyai tegangan tarik paling tinggi dan banyak digunakan untuk material tools. Salah satu aplikasi dari baja ini adalah dalam pembuatan kawat baja dan kabel baja. Berdasarkan jumlah karbon yang terkandung didalam baja maka baja karbon ini banyak digunakan dalam pembuatan pegas, alat-alat perkakas seperti palu, gergaji atau pahat potong (Dieter 2011).

Proses perlakuan panas (Heat Treatment) adalah suatu proses mengubah sifat logam dengan cara mengubah struktur mikro melalui proses pemanasan dan pengaturan kecepatan pendinginan dengan atau tanpa merubah komposisi kimia logam yang bersangkutan. Tujuan proses perlakuan panas untuk menghasilkan sifat-sifat logam yang diinginkan. Perubahan sifat logam akibat proses perlakuan panas dapat mencakup keseluruhan bagian dari logam atau sebagian dari logam. Adanya sifat alotropik dari besi menyebabkan timbulnya variasi struktur mikro dari berbagai jenis logam. Alotropik itu sendiri adalah merupakan transformasi dari satu bentuk susunan atom (sel satuan) ke bentuk susunan atom yang lain(Iman et al. 2018).

Perlakuan juga bertujuan untuk meningkatkan keuletan, menghilangkan tegangan internal (internal stress), menghaluskan ukuran butir kristal dan meningkatkan kekerasan atau tegangan tarik logam (Suratman, 1994).

Beberapa faktor yang dapat mempengaruhi perlakuan panas, yaitu temperatur pemanasan, waktu yang diperlukan pada suhu pemanasan, laju pendinginan dan 
Murtalim, Fathan Mubina Dewadi, Amir, Wanri Saputra Sigalingging

Vol. 5 No 2

ISSN : 2541-6995

E ISSN : 2580-5517

lingkungan atmosfir. Salah satu proses perlakuan panas pada baja adalah pengerasan (hardening), yaitu proses pemanasan baja sampai suhu di daerah atau diatas daerah kritis disusul dengan pendinginan yang cepat dinamakan quenching (Murtiono 2012).

Diagram fasa adalah diagram yang menghubungkan antara temperatur dengan kadar karbon, dimana terjadi perubahan fasa pada saat proses pemanasan atau pendinginan. Diagram fasa $\mathrm{Fe}-\mathrm{C}$ merupakan diagram yang menjadi parameter untuk mengetahui segala jenis fasa yang terjadi di dalam baja, serta untuk mengetahui faktor - faktor apa saja yang terjadi di dalam baja paduan dengan berbagai jenis perlakuan (Campostlon (ater $)^{2}$ ) 2007)

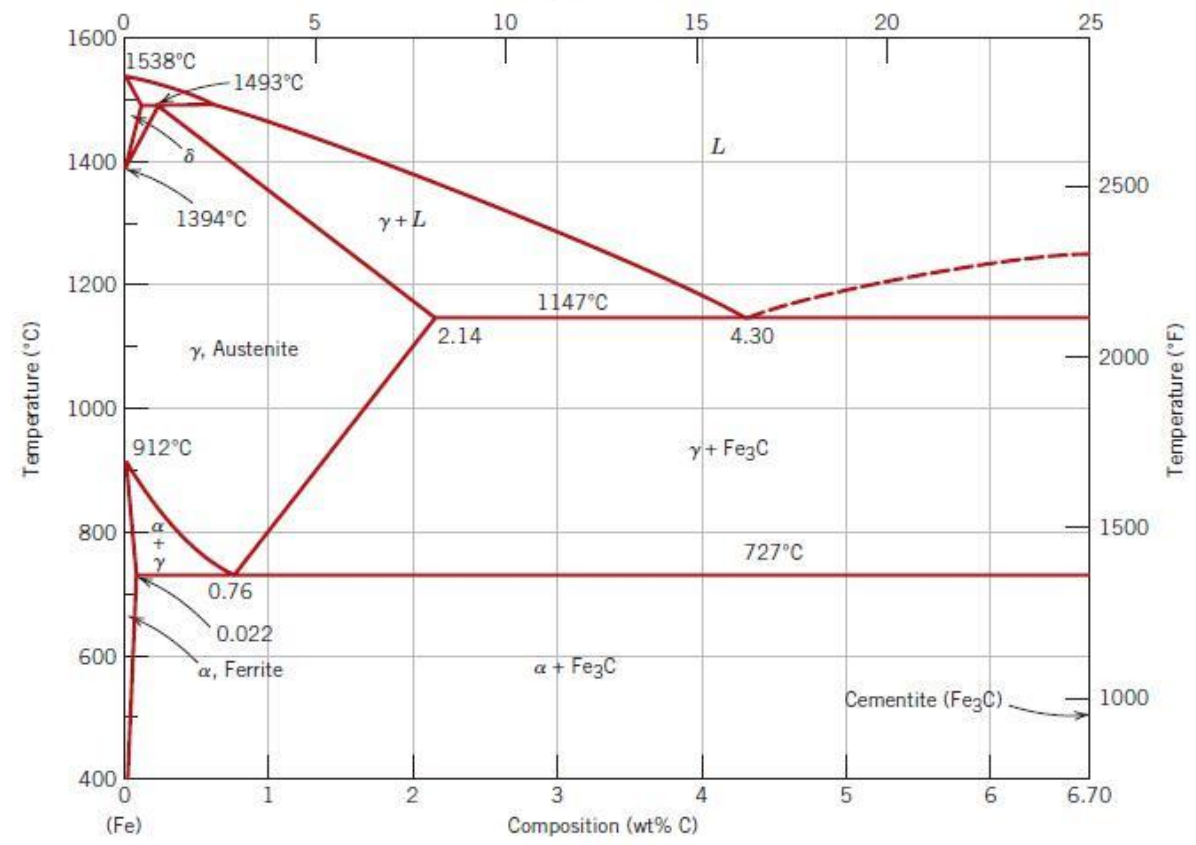

Gambar 1. Diagram fasa Fe-C. (Callister 2007)

Maksud utama dari proses perlakuan panas terhadap baja adalah agar diperoleh struktur yang diinginkan supaya cocok dengan penggunaan yang direncanakan. Struktur tersebut dapat diperkirakan dengan cara menerapkan proses perlakuan panas yang spesifik. Struktur yang diperoleh merupakan hasil dari proses transformasi dari kondisi sebelumnya (awal). Beberapa proses transformasi dapat dibaca melalui diagram fasa. Diagram fasa $\mathrm{Fe}-\mathrm{C}$ dapat digunakan untuk memperkirakan beberapa kondisi transformasi tetapi untuk kondisi tidak setimbang tidak dapat menggunakan diagram fasa. Dengan demikian, untuk setiap kondisi 
Murtalim, Fathan Mubina Dewadi, Amir, Wanri Saputra Sigalingging

Vol. 5 No 2

ISSN : 2541-6995

E ISSN : 2580-5517

transformasi lebih baik menggunakan diagram TTT (Time - Temperature Transformation). Diagram ini menghubungkan transformasi austenit terhadap waktu dan temperatur. Nama lain dari diagram ini adalah diagram $\mathrm{S}$ atau diagram C. Melalui diagram ini dapat dipelajari kelakuan baja pada setiap tahap perlakuan panas. Diagram ini dapat juga digunakan untuk memperkirakan struktur dan sifat mekanik dari baja yang diquench (disepuh) dari temperatur austenitisasinya ke suatu temperatur dibawah A1. Pengaruh laju pendinginan pada transformasi austenit dapat diuraikan melalui penggunaan diagram TTT untuk jenis baja tertentu. Pada diagram ini sumbu tegak menyatakan temperatur sedangkan sumbu datar menyatakan waktu yang diplot dalam skala logaritmik. Diagram ini merupakan ringkasan dari beberapa jenis struktur mikro yang diperoleh dari rangkaian percobaan yang dilakukan pada spesimen yang kecil yang dipanaskan pada temperatur austenitisasinya, kemudian diquench pada temperatur tertentu dibawah titik eutektoid A1, untuk jangka waktu yang tertentu pula sampai seluruh austenit bertransformasi. Proses transformasi dari austenit pada baja yang bersangkutan diamati dan dipelajari dengan menggunakan mikroskop (Iman et al. 2018)

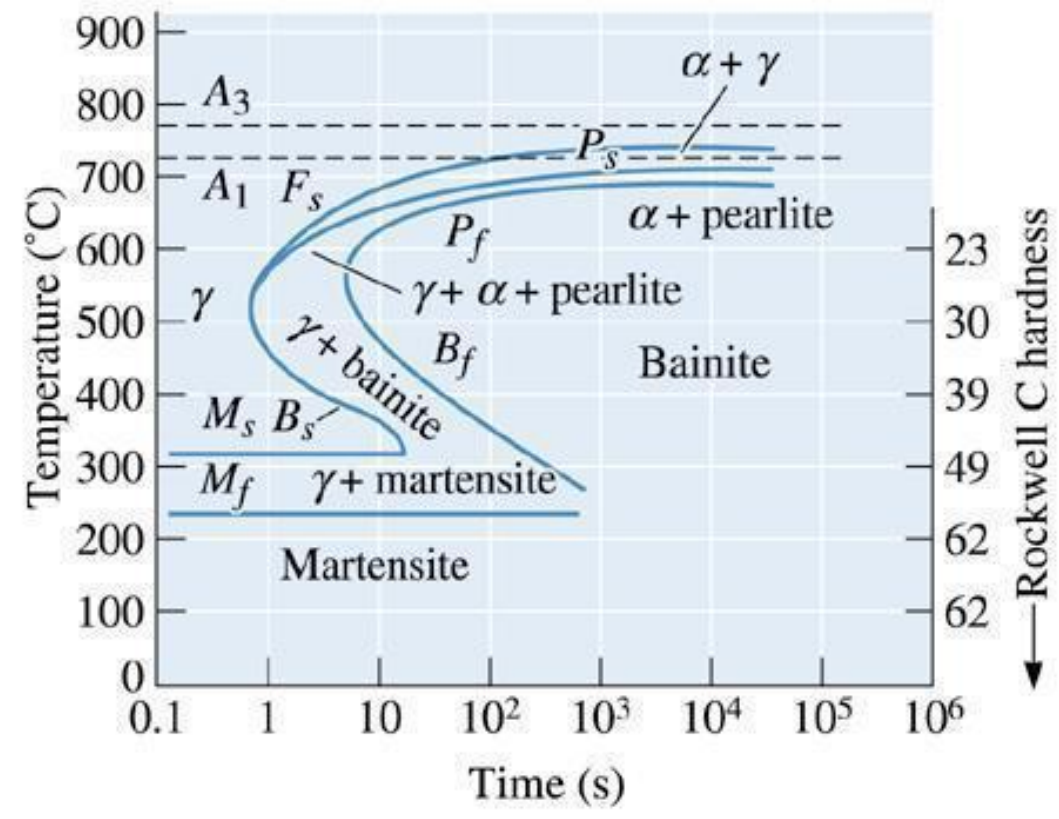

Gambar 2. Diagram TTT (Time Temperature Transformation)untuk baja hipoeuutektoid (Kandungan Carbon maksimal 0,6 \%) (Callister 2007) 
Murtalim, Fathan Mubina Dewadi, Amir, Wanri Saputra Sigalingging

Vol. 5 No 2

ISSN : 2541-6995

E ISSN : 2580-5517

Pengujian komposisi kimia pada material dilakukan untuk mengetahui komposisi kimia yang terkandung pada material tersebut apakah komposisi tersebut sesuai dengan spesifikasi yang ditentukan untuk desain. Pengujian ini sekurang-kurangnya meliputi unsur besi (Fe), karbon (C), nikel (Ni), sulfur (S), Mangan (Mn), molybdenum (Mo), chrom (Cr),dan silicon (Si). Alat yang digunakan untuk mengetahui komposisi kimia tersebut yaitu optical emission spectrometer. Tahapan-tahapan dalam melakukan pengujian komposisi kimia dengan menggunakan spektometer yaitu benda yang akan diuji setelah dilakukan pemotongan dan dihaluskan/dihampelas kemudian diletakkan pada tempat sampel dan kemudian spray permukaan material dengan gas argonmurni sampai 99,99\%.

Pengujian dilakukan dengan menarik batang uji perlahan-lahan sampai patah, sementara beban dan jarak panjang ukur dimonitor secara kontinyu.

Hasil uji tarik dapat ditampilkan dalam bentuk kurva "Tegangan-regangan”. Sifatsifat material yang dapat ditentukan dari uji tarik adalah :
a) Modulus elastisitas
b) Batas elastis (elastic limit)
c) Kekuatan luluh (Yield Strength)
d) Kekuatan tarik ultimat (Ultimate Tensile Strength)

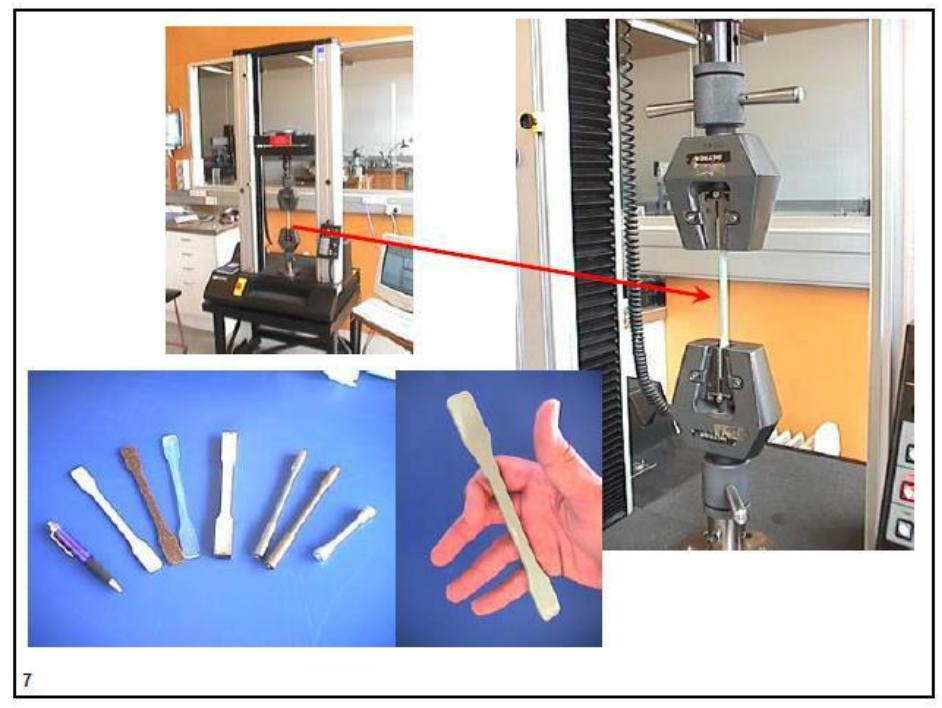

Gambar 3 Mesin uji Tarik

Uji keras dilakukan untuk mendapatkan sifat kekerasan material. Kekerasan biasanya dapat dinyatakan dalam tiga skala yaitu Brinell, Rockwell, atau Vickers. 
Murtalim, Fathan Mubina Dewadi, Amir, Wanri Saputra Sigalingging

Vol. 5 No 2

ISSN : 2541-6995

E ISSN : 2580-5517

Perbedaan utama dari ketiga skala ini adalah pada beban dan indentor yang digunakan dalam pengukurannya. Masing-masing skala ini mempunyai kelebihan dimana Vickers hanya butuh satu setup pengujian untuk semua material, Rockwell akan memberikan kesalahan operator yang lebih kecil karena tidak perlu mikroskop, sedangkan Brinell dapat dengan mudah dikonversikan kedalam kekuatan tarik ultimate-nya.
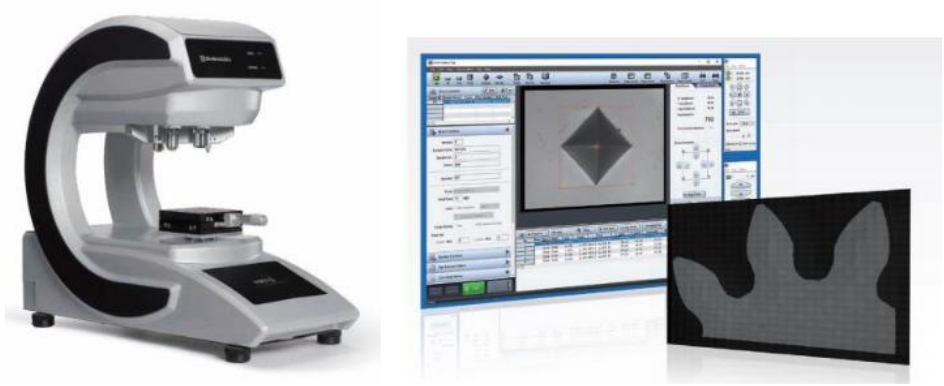

Gambar 4 Alat mesin uji Mesin uji keras Micro Vickers Hardness Tester

Pengujian metalografi adalah suatu teknik atau ilmu untuk melihat struktur mikro dan makro material. Struktur mikro logam dapat diperoleh melalui proses penyiapan spesimen metalografi. Dengan tujuan untuk menganalisa struktur, Mengenali fasa-fasa dalam struktur mikro, berdasarkan skala makro maupun skala mikro.

\section{METODE PENELITIAN}

Metode penelitian yang digunakan adalah metode eksperimen yang dilakukan di Lab.Metalurgi Teknik Mesin Fakultas Teknik dan Ilmu Komputer (FTIK) Universitas Buana Perjuangan Karawang dengan penekanan pada karakteristik uji tarik, uji keras dan uji metalografi, serta untuk uji kompsosi kimia dilakukan di PT Dynatec Bekasi.

Dari hasil pengukuran dan pengujian dapat diperoleh data hasil sebagai berikut :

- Material Rear hub spindles

Rear hub spindles adalah komponen suku cadang as roda belakang sepeda, berdasarkan data dari agen penjual suku cadang dan literataur diperoleh spesifikasi material : Deskripsi AS HUB BICYCLE SPINDLE BEARING 17.8 $\mathrm{cm}+\mathrm{AS} /$ SPINDLE 
Murtalim, Fathan Mubina Dewadi, Amir, Wanri Saputra Sigalingging

Vol. 5 No 2

ISSN : 2541-6995

E ISSN : 2580-5517

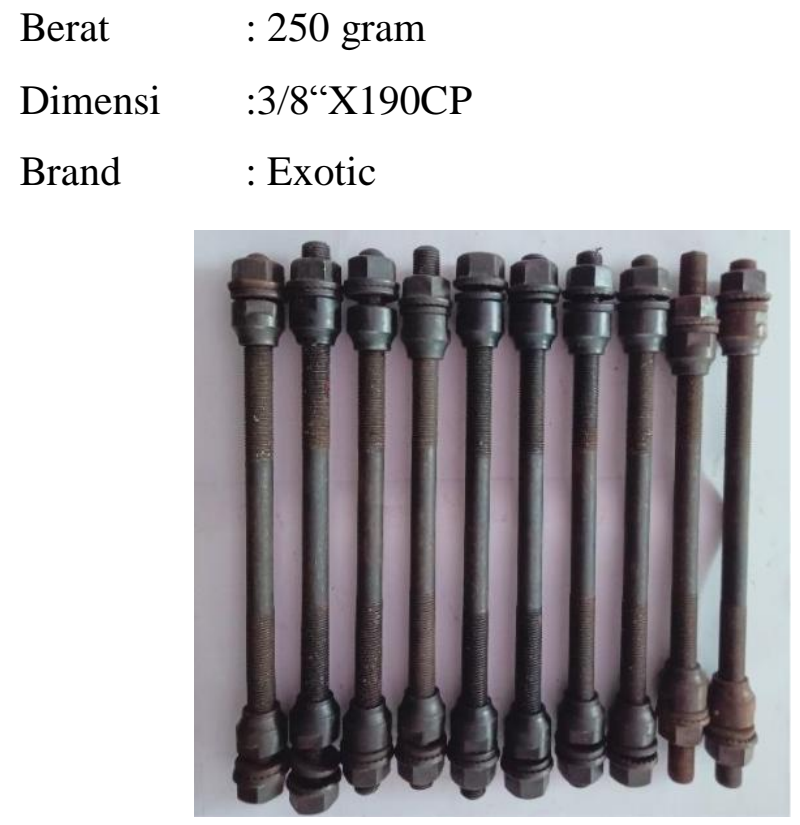

Gambar 5. Rear hub spindles

- Proses perlakuan panas

Pemanasan awal memberikan pengaruh pada sifat mekanis bahan. Setelah dipanaskan pada masing-masing v a r i a s i temperature $825^{\circ} \mathrm{C}, 850{ }^{\circ} \mathrm{C}, 875$ ${ }^{\circ} \mathrm{C}$, spesimen didinginkan dengan media pendingin oli . Dalam penelitian ini digunakan thermocouple digital untuk mendapatkan pembacaan suhu yang akurat di dalam furnace.
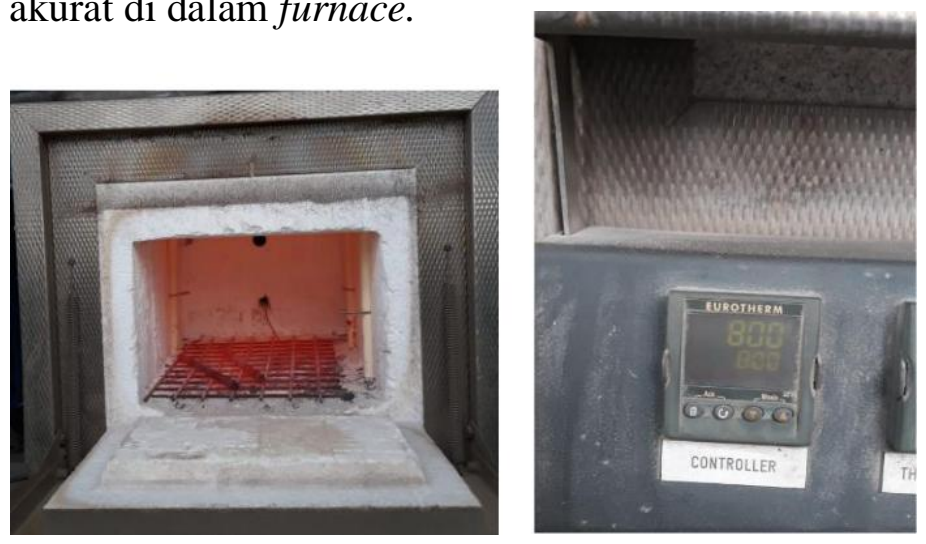

Gambar 6. Furnace Nabertherm GmbH untuk proses perlakuan panas 
Murtalim, Fathan Mubina Dewadi, Amir, Wanri Saputra Sigalingging

Vol. 5 No 2

ISSN : 2541-6995

E ISSN : 2580-5517

Variasi :

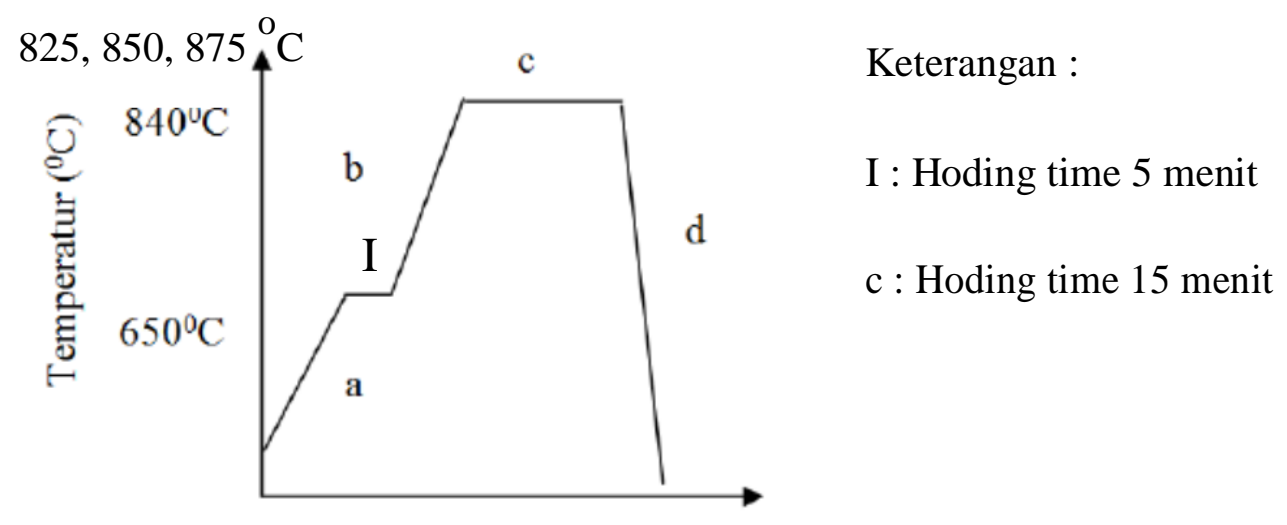

Waktu (menit)

Gambar 7 Proses Perlakuan Panas Pada material baja Karbon rendah

- Uji Komposisi Kimia

Bahan digunakan dalam penelitian ini adalah rear hub spindles dengan hasil uji spektrometri sebagai berikut:

Tabel 1. Komposisi kimia dari material rear hub spindle yang telah melalui uji spektrometri

\begin{tabular}{|c|c|c|c|c|c|c|c|c|c|}
\hline \multicolumn{10}{|c|}{ Nama Unsur ( Perentase) } \\
\hline $\mathrm{Fe}(\mathrm{g}$ & 6) $\mathrm{C}(9$ & Si (\% & Mn I & $P(\%)$ & $S(\%)$ & $\operatorname{Cr}(\%)$ & Mo (\%) & $i(\%)$ & $\%$ \\
\hline 99,0000 & 0,1750 & 0,1700 & 0,5597 & 0,0035 & 0,0139 & 0,0156 & 0,0030 & $<0,005$ & $<0,002$ \\
\hline
\end{tabular}

- Uji Tarik

Uji tarik menggunakan standar specimen menurut ASTM E8 dengan kapasitas mesin uji tarik $10 \mathrm{kN}$, diperoleh data-data sebagai berikut :

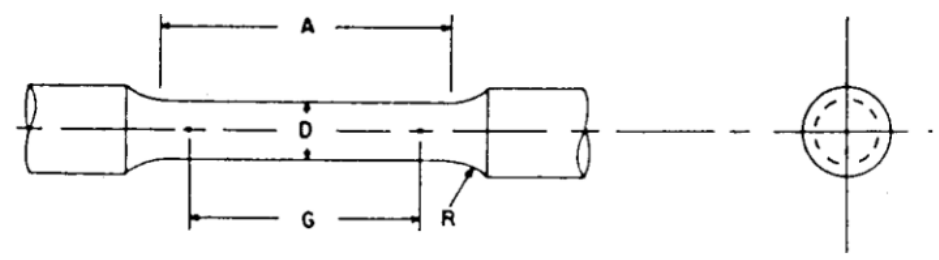

\begin{tabular}{|l|c|}
\hline \multicolumn{1}{|c|}{ Dime nsion } & Spesimen $(\mathbf{m m})$ \\
\hline \hline$G$-Gage length & $16.0 \pm 0.1$ \\
\hline & {$[0.640 \pm 0.005]$} \\
\hline D-Diameter (Note 1) & $4.0 \pm 0.1$ \\
\hline & {$[0.160 \pm 0.003]$} \\
\hline$R$ - Radius of fillet, min & $4[0.156]$ \\
\hline A- Length of reduced section, min (Note 2) & $20[0.75]$ \\
\hline
\end{tabular}

Gambar 8. Dimensi sampel untuk uji tarik menurut standart ASTM E8M (ASTM E8 2010) 
Murtalim, Fathan Mubina Dewadi, Amir, Wanri Saputra Sigalingging

Vol. 5 No 2

ISSN : 2541-6995

E ISSN : 2580-5517

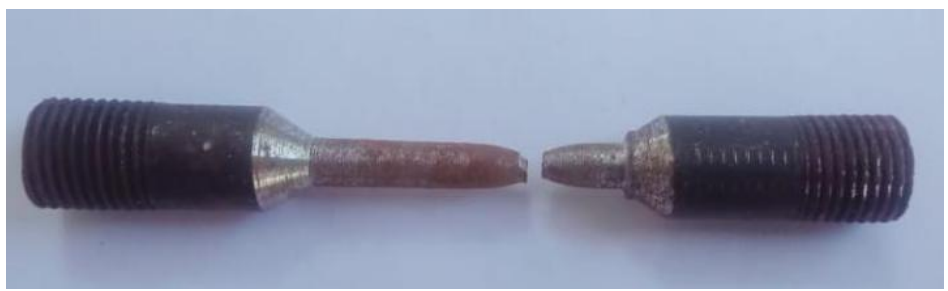

Gambar 9. Foto sampel untuk specimen yang telah mengalami uji tarik

Tabel 2. Nilai hasil tegangan rata-rata pada sampel uji tarik.

\begin{tabular}{|c|c|c|c|c|c|}
\hline \multirow{2}{*}{$\begin{array}{l}\text { Name } \\
\text { Parameters }\end{array}$} & \multicolumn{2}{|c|}{ Max_Force } & \multicolumn{2}{|c|}{ Max_Stress } & \multirow{2}{*}{$\begin{array}{l}\text { Elastic } \\
\text { Force } 10-20 \mathrm{~N}\end{array}$} \\
\hline & $\begin{array}{l}\text { Calc. } \\
\text { Entire }\end{array}$ & at & $\begin{array}{l}\text { Calc. } \\
\text { Entire }\end{array}$ & at & \\
\hline Unit & $\mathrm{N}$ & & $\mathrm{N} / \mathrm{mm}^{2}$ & & $\mathrm{~N} / \mathrm{mm}^{2}$ \\
\hline Tanpa heat treatment & 7553,60 & & 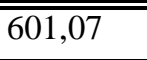 & & 304,86 \\
\hline $825^{\circ} \mathrm{C}$ & 7092,81 & & 537,50 & & 328,75 \\
\hline $850 \mathrm{C}$ & 7414,03 & & 575,00 & & 395,43 \\
\hline $875 \mathrm{C}$ & 7949,94 & & 602,46 & & 1067,90 \\
\hline
\end{tabular}

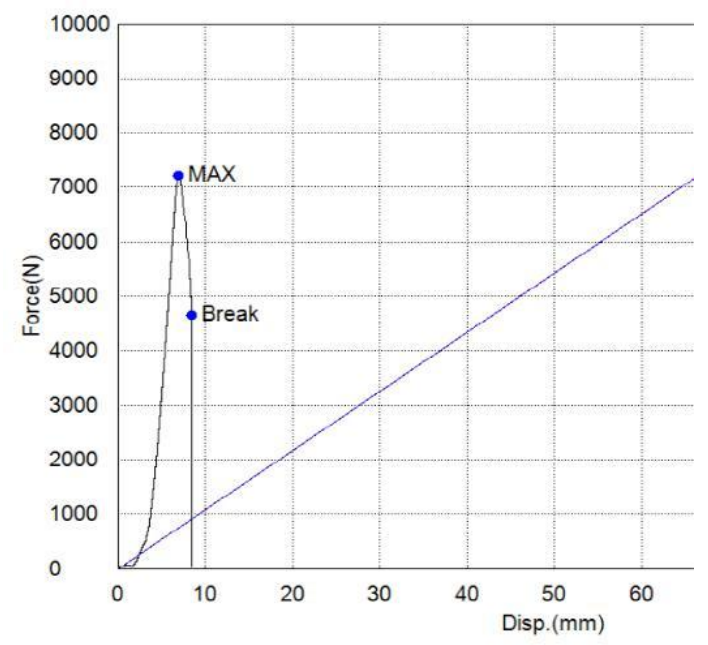

Gambar 10. Kurva uji Tarik Gaya- displacement material tanpa perlakuan panas 
Murtalim, Fathan Mubina Dewadi, Amir, Wanri Saputra Sigalingging

Vol. 5 No 2

ISSN : 2541-6995

E ISSN : 2580-5517

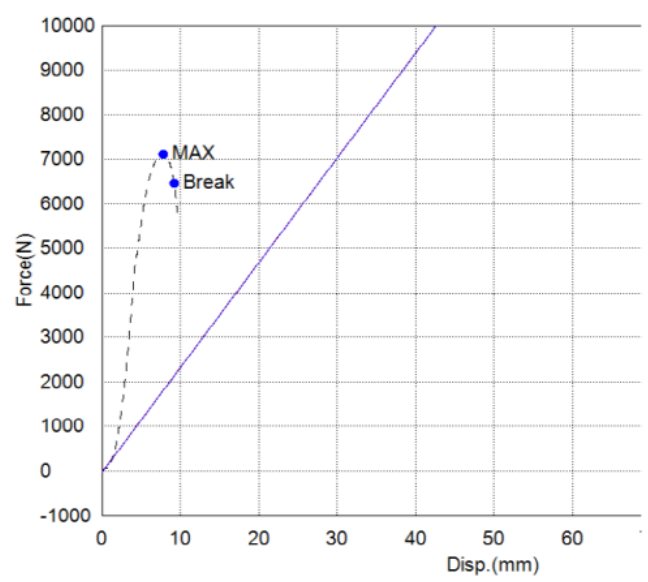

a) $825^{\mathrm{O}} \mathrm{C}$

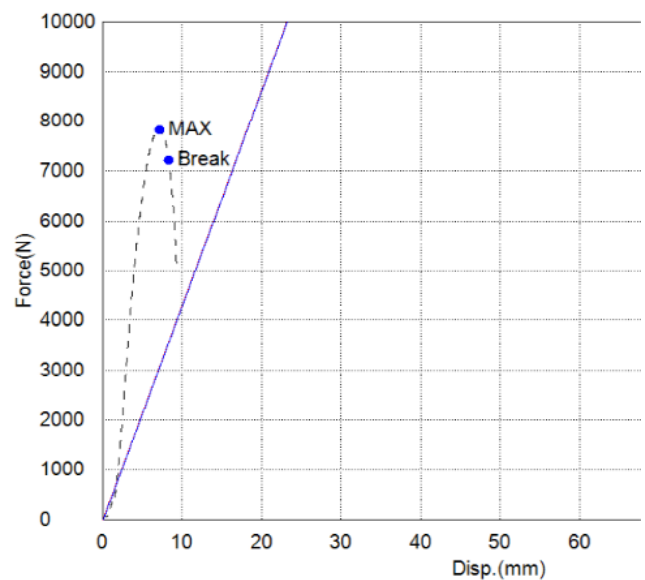

b) $850{ }^{\mathrm{O}} \mathrm{C}$

Gambar 11. Kurva uji Tarik Gaya- displacement material untuk perlakuan panas pada temeratur a). $\left.825{ }^{\mathrm{O}} \mathrm{C}, \mathrm{b}\right) 850{ }^{\mathrm{O}} \mathrm{C}$

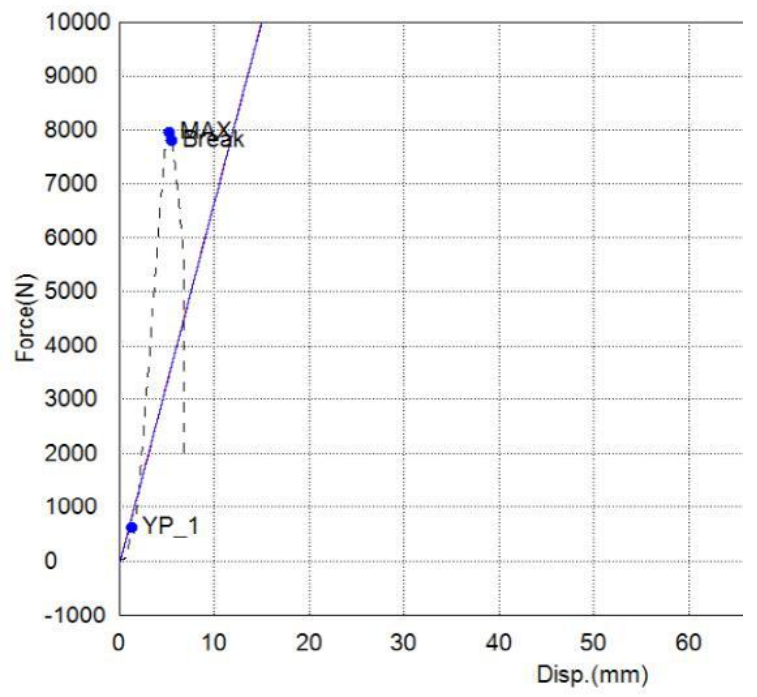

Gambar 12. Kurva uji Tarik Gaya- displacement material untuk perlakuan panas pada temeratur $875{ }^{\mathrm{O}} \mathrm{C}$

\section{- Uji Keras}

Pengujian kekerasan menggunakan metode Vickers atau HV (Hardness Vickers) dengan intan sebagai indentor dan diperoleh data-data sebagai berikut : 
Murtalim, Fathan Mubina Dewadi, Amir, Wanri Saputra Sigalingging

Vol. 5 No 2

ISSN : 2541-6995

E ISSN : 2580-5517

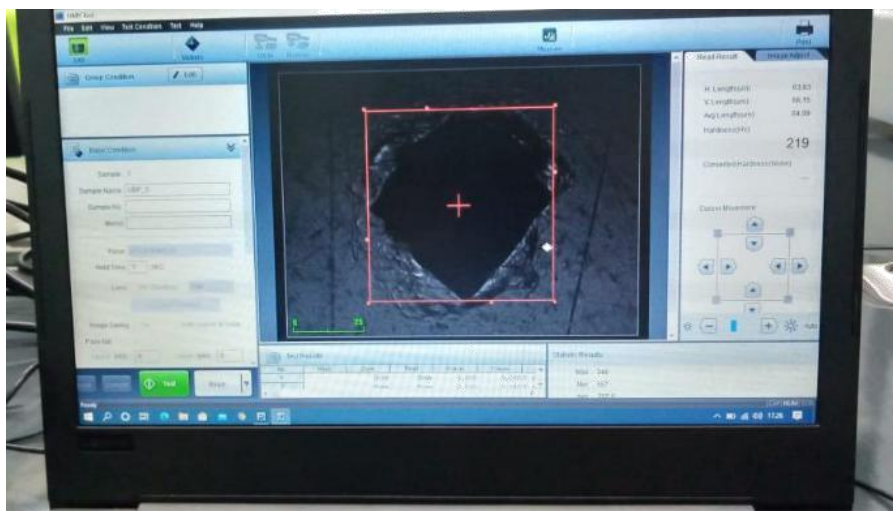

Gambar 13. Hasil uji nilai kekerasan rata-rata dengan metode Vickers

Tabel 3. Nilai hasil uji keras micro hardness vickers

\begin{tabular}{|c|c|c|}
\hline No. & Temperature & Nilai kekerasan (HVN) \\
\hline \hline 1 & Tanpa Heat Treatment & 223 \\
\hline 2 & 825 & 168 \\
\hline 3 & 850 & 175 \\
\hline 4 & 875 & 219 \\
\hline
\end{tabular}

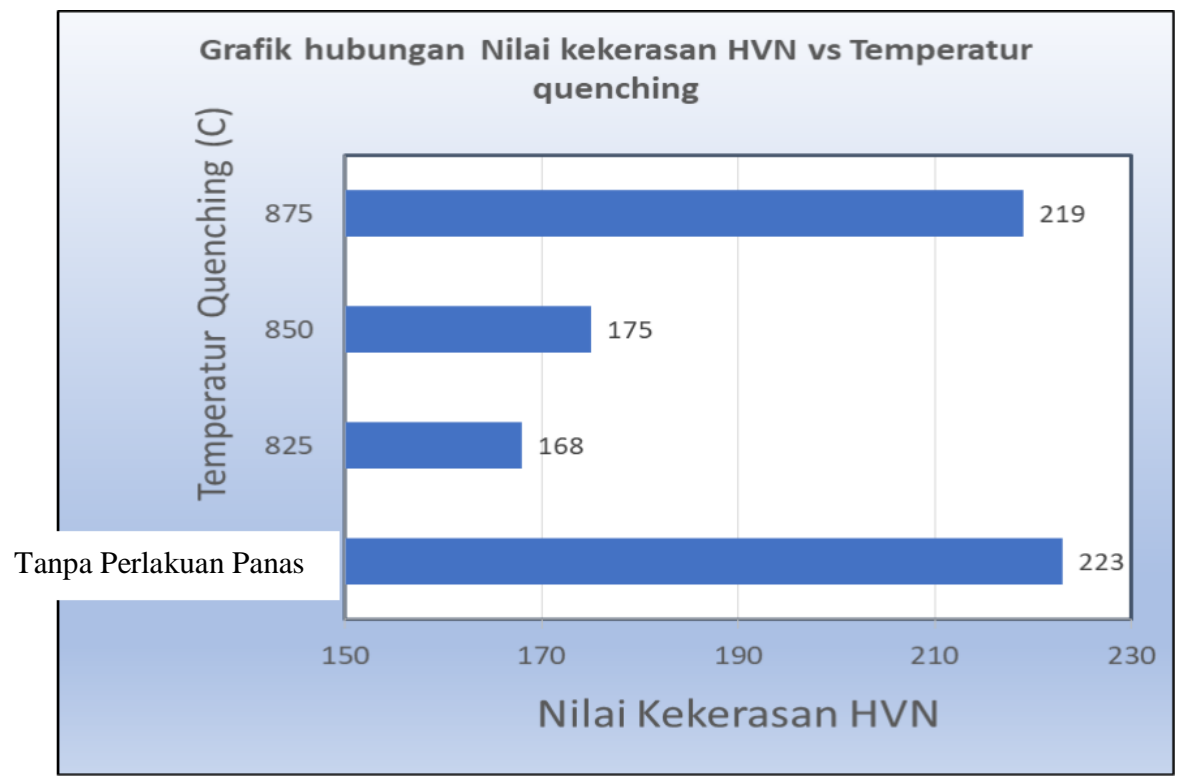

Gambar 14. Grafik hubungan nilai kekerasan 
Murtalim, Fathan Mubina Dewadi, Amir, Wanri Saputra Sigalingging

Vol. 5 No 2

ISSN : 2541-6995

E ISSN : 2580-5517

- Uji Metaligrafi

Setelah dilakukan uji metalografi maka

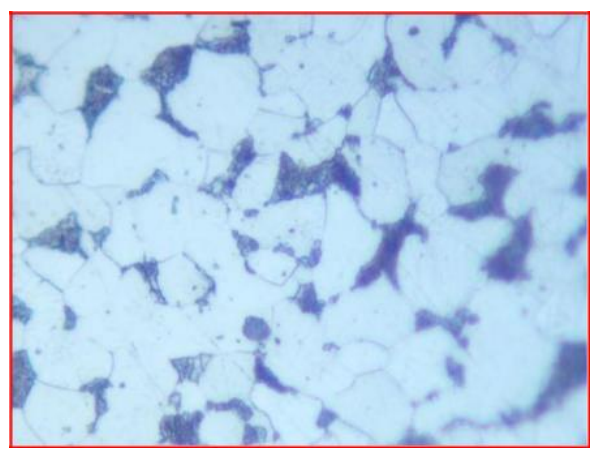

Gambar 15. Hasil uji metalografi material tanpa proses perakuan panas denga pembsaran $800 \mathrm{X}$
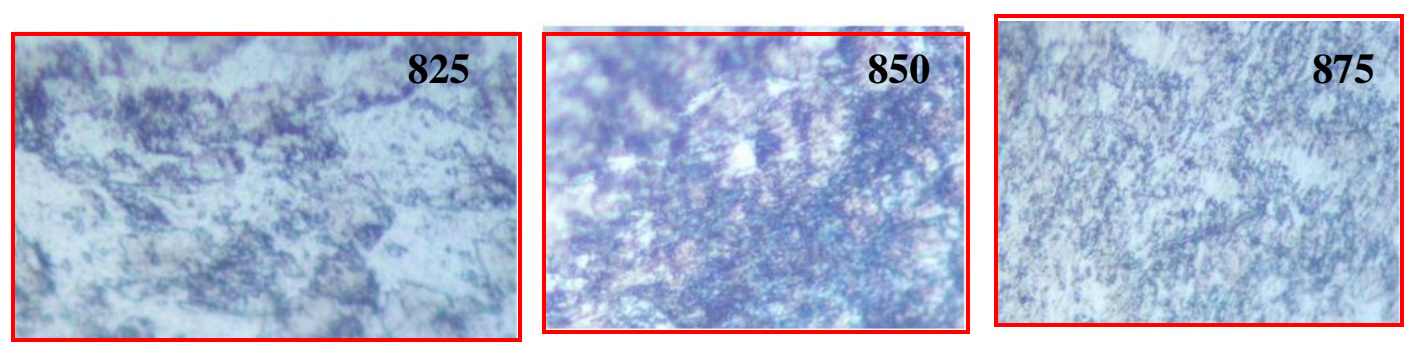

Gambar 16. Hasil uji metalografi (pembsaran $800 \mathrm{X}$ ) material yang telah mengalami proses quenching dengan temperatur pemanasan masing masing $825^{\circ} \mathrm{C}, 850{ }^{\circ} \mathrm{C}, 875$ ${ }^{\mathrm{o}} \mathrm{C}$

Rancangan percobaan yang dipilih adalah Pre Eksperimental Designs bertipe Static Group Comparations, jadi ada kelompok percobaan/eksperimen dan kelompok kontrol. Kelompok eksperimen terdiri dari sampel yang telah mengalami perlakuan panas yaitu sampel uji tarik, uji keras dan uji metalografi masing-masing berjumlah 9 sampel. Eksperimen untuk kelompok kontrol (raw materials) dilakukan sebagai pembanding sebanyak 3 sampel.

Penelitian difokuskan untuk mengetahui perbedaan sifat mekanik dan struktur mikro yang terjadi antara material yang telah diberi perlakuan panas dengan variasi temperature $825{ }^{\circ} \mathrm{C}, 850{ }^{\circ} \mathrm{C}$ dan $875^{\circ} \mathrm{C}$ dengan media pendingin oli.

Analisa hasil penelitian ini akan di lakukan berdasarkan metodologi yang di susun merujuk pada rumusan masalah dan batasan masalah yang di rangkai dalam 
Murtalim, Fathan Mubina Dewadi, Amir, Wanri Saputra Sigalingging

Vol. 5 No 2

ISSN : 2541-6995

E ISSN : 2580-5517

susunan kerangka pemikiran yang terorganisir dalam flowcart atau diagram alir di bawah ini.

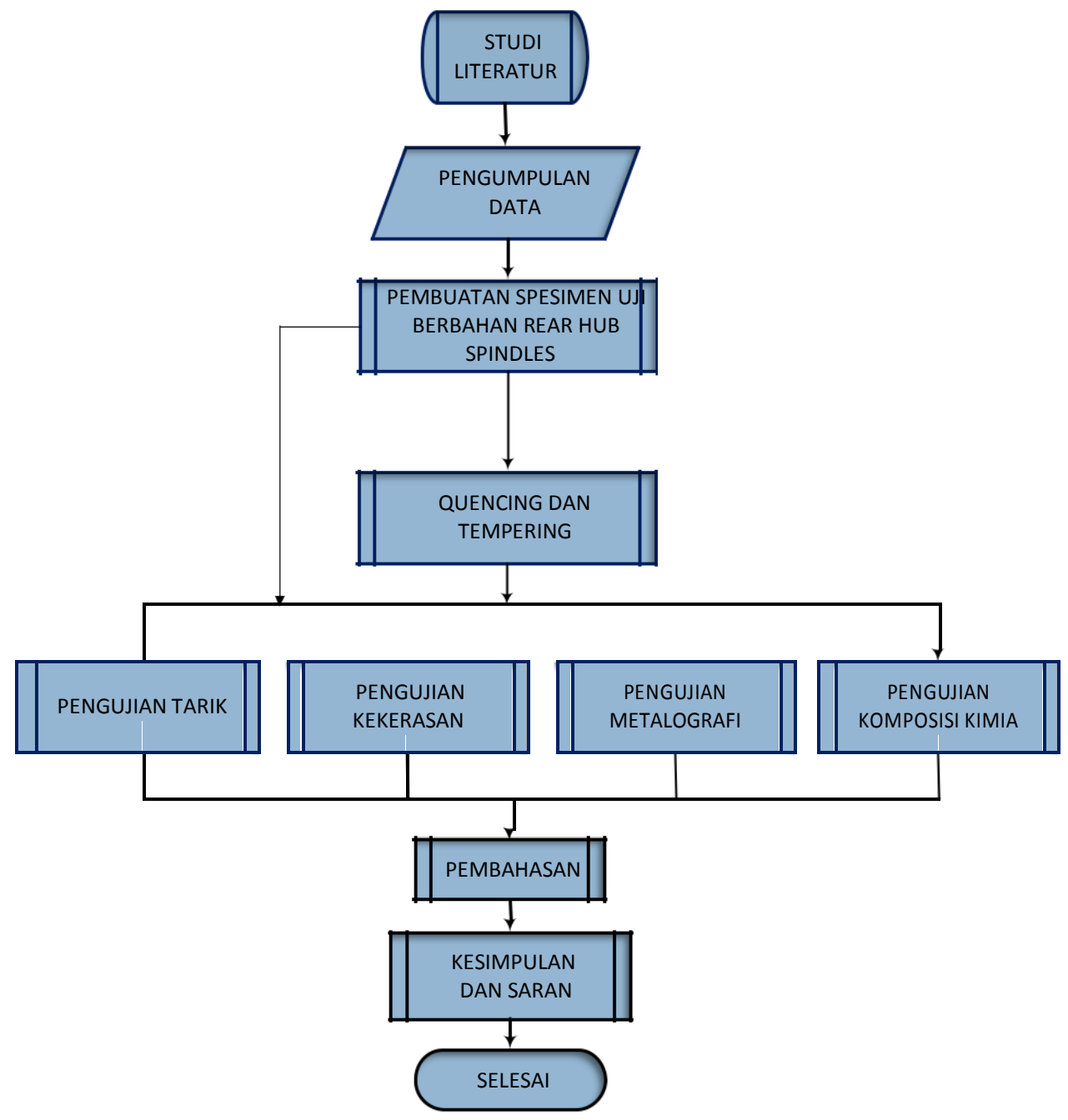

Gambar 17. Diagram Alir proses penelitian 


\section{HASIL DAN PEMBAHASAN}

Dari hasil pengujian yang berdasarkan metode penelitian yang telah diterapkan maka diperoleh pembahasan sebagai berikut :

1. Dari pengujian spektrometri yang telah dilakukan diperoleh data yang menunnjukan bahwa material rear hub spindles yang digunakan untuk material gigi mesin perontok padi memiliki kandungan carbon 0,1750\% $\mathrm{C}$ oleh karena itu termasuk dalam kaagori material baja karbon rendah (Baja hipoeutectoid), hal ini menjadi acuan untuk menentukan temperature pemanasan quenchingnya.

2. Metode perlakuan panas yang diterapkan untuk material rear hub spindles dengan kandungan komposisi karbonnya yang rendah adalah proses quenching dengan media pendingin oli dan menerapkan tiga variasi temperatur yaitu 825

${ }^{\mathrm{o}} \mathrm{C}, 850{ }^{\mathrm{o}} \mathrm{C}$ dan $875{ }^{\circ} \mathrm{C}$, hal ini bertujuan untuk mengetahui nilai temperatur pemanasan yang tepat dan optimal agar dapat meningkatkan sifat mekanik material tersebut, hasil pengujian yang diperoleh juga nanti akan dibandingkan dengan material yang tanpa diproses perlakuan panas.

3. Dari hasil proses pengujian sifat mekanik material rear hub spindles terhadap kekuatan tariknya (max Stress) bahan memperlihatkan nilai kekuatan tarik material yang tidak mengalami proses quenching adalah 601,06 N/mm ${ }^{2}$ sedangkan untuk spesimen dengan nilai kekuatan tarik tertingi terdapat pada spesimen uji yang diberi perlakuan panas pada temperatur $875{ }^{\circ} \mathrm{C}$ dengan nilai kekuatan $602,46 \mathrm{~N} / \mathrm{mm}^{2}$

4. Sifat mekanik berupa nilai kekerasan bahan baja karbon rendah sebelum mengalami proses quenching adalah $223 \mathrm{HVN}$, hasil uji kekerasan maksimum sebesar $219 \mathrm{HVN}$ terdapat pada material setelah mengalami proses quenching pada temperaturepemanasan $875{ }^{\circ} \mathrm{C}$. Nilai kekerasan baja karbon rendah semakin meningkat seiring bertambahnya temperatur pemanasan (Nurlina, Nila 2019)

5. Setelah mengalami prosesperlakuan panas, butir-butir akan mengalami perubahan bentuk dan ukuran. Hubungan antara ukuran butiran dengan kekerasan dan kekuatan tarik berbanding terbalik, dimana semakin kecil 
Murtalim, Fathan Mubina Dewadi, Amir, Wanri Saputra Sigalingging

Vol. 5 No 2

ISSN : 2541-6995

E ISSN : 2580-5517

ukuran butiran maka bahan semakin keras dan kekuatan tariknya makin tinggi dan hal ini sesuai dengan Hall and Petch Method (Murtiono 2012),

\section{KESIMPULAN DAN IMPLIKASI}

Dari hasil data dan pembahasan yang telah dilakukan maka dapat diperoleh kesimpulan sebagai berikut :

1. Setelah melakukan proses perlakuan panas quenching terhadap material rear hub spindles (as roda belakang sepeda) maka terdapat hubungan antara temperatur proses perlakuan panasnya dengan ukuran butiran, kekerasan dan kekuatan tarik dimana semakin tinggi temperature proses perakuan panas yaitu

pada temperatur $875{ }^{\circ} \mathrm{C}$, maka akan semakin kecil ukuran butiran sehingga kekuatan tarik dan kekerasan material rear hub spindles semakin meningkat.

2. Temperatur proses perlakuan panas yang rendah untuk material malah justru akan menurunkan kekuatan dan kekerasan material tersebut, hal itu dibuktikan dengan terjadinya penurunan nilai kekerasan dan kekuatan tarik pada material yang haya diberikan temperatur $825^{\circ} \mathrm{C}$ dan $850{ }^{\circ} \mathrm{C}$.

3. Material rear hub spindles yang telah megalami proses perlakuan panas quenching ditemperatur $875{ }^{\circ} \mathrm{C}$ dengan media pendinginnya oli telah meningkat kekuatan sifat mekaniknya maka selanjutnya bisa dijadikan sebagai alternatif suku cadang untuk gigi mesin perontok padi oleh para petani dan pengusaha mesin perontok padi di kecamatan Batujaya kabupaten Karawang Jawabarat,

Penelitian selanjutnya disarankan melakukan proses perlakun panas quench temper serta menggunakan variasi media pendingin yang lebih beragam agar lebih jelas perbedaan sifat fisik, mekanik dan struktur mikro yang terjadi pada material rear hub spindles yang termasuk dalam katagori baja carbon rendah. Penggunaan media pendingina air lebih cepat mengalami perubahan struktur mikropada logam dibanding pendinginan dengan media oli (Mesin 2015) 
Murtalim, Fathan Mubina Dewadi, Amir, Wanri Saputra Sigalingging

Vol. 5 No 2

ISSN : 2541-6995

E ISSN : 2580-5517

\section{DAFTAR PUSTAKA}

Ali, Akhwan. 2017. "Pengaruh Teknologi Pertanian Terhadap Produktivitas Hasil Panen Padi Di Kecamatan Maritengngae Kabupaten Sidenreng Rappang.” Jurnal Ilmiah 14(3):514-25.

ASTM E8. 2010. “ASTM E8/E8M Standard Test Methods for Tension Testing of Metallic Materials 1.” Annual Book of ASTM Standards 4 (C):1-27.

Callister. 2007. Materials Science and Engineering.

Dieter, George Ellwood. 2011. "Mechanical Metallurgy." Mechanical Metallurgy.

Iman, Saefuloh, Haryadi, Abdurrofi Zahrawani, and Bintang Adjiantoro. 2018.

"Pengaruh Proses Quenching Dan Tempering Terhadap Sifat Mekanik Dan

Struktur Mikro Baja Karbon Rendah Dengan Paduan Laterit.” Jurnal Teknik Mesin 4(1):56-64.

Mesin, Jurusan Teknik. 2015. "Metoda Quenching Dan Media Pendingin Terhadap.” Jurnal Teknik Mesin, Institut Teknologi Padang Vol.5, No.:5964.

Murtiono, Arief. 2012. "Pengaruh Quenching Dan Tempering Terhadap Kekerasan Dan Kekuatan Tarik Serta Struktur Mikro Baja Karbon Sedang Untuk Mata Pisau Pemanen Sawit.” E-Dinamis II(2):57-70.

Nurlina, Nila, 2019. 2019. "Pengaruh Pengujian Hardening Pada Baja Karbon Rendah Sebagai Solusi Peningkatan Kualitas Material.” Jurnal Qua Teknika, (2019), 9(1) : 11-20 Vol. 9.

Sulistiaji, Koes. 2007. "Buku Alat Dan Mesin (Alsin) Panen Dan Perontokan Padi Di Indonesia." 45.

Suratman, Rochim. n.d. "Panduan Proses Perlakuan Panas", Jurusan Teknik Mesin Unpas, Bandung, 1994. 
Murtalim, Fathan Mubina Dewadi, Amir, Wanri Saputra Sigalingging

Vol. 5 No 2

ISSN : 2541-6995

E ISSN : 2580-5517 